\title{
Las trampas de lo audiovisual en la enseñanza
}

Por Hebe I rene Roig*

\section{Resumen}

En el presente artículo se presentan resultados de investigación sobre el uso de lo audiovisual en contextos de enseñanza de las Ciencias Sociales en el nivel superior. Lo audiovisual, culturalmente situado en las formas cotidianas de comunicación, convoca lecturas del sentido común que tienden trampas al desarrollo de una enseñanza orientada al pensamiento complejo y crítico. A partir de la observación de clases, entrevistas a docentes y entrevistas y encuestas a alumnos, analizamos algunas implicaciones de la mediación docente sobre las lecturas que los estudiantes hacen de lo audiovisual. Contrariamente a la creencia del sentido común de muchos docentes y alumnos, el trabajo con lo audiovisual en clase no es "fácil". Para que esta actividad sea una herramienta poderosa en el ejercicio del pensamiento complejo se han de sortear algunas trampas que nos tienden las lecturas espontáneas de lo audiovisual ya que ellas ponen en juego la necesidad del pasaje de las concepciones ingenuas al pensamiento disciplinar.

\begin{abstract}
The results of research on the use of audiovisual material in the teaching of Social Sciences in higher education are herein presented. Audiovisual texts, which are culturally within the everyday forms of communication, summon commonsense readings which set traps for the teaching of complex and critical thought. Based on class observation, interviews with teachers, and interviews and surveys of students, some implications of the mediation of the teacher in the readings of audiovisual texts by the students are analyzed. Contrary to the commonsense belief of many teachers and students, working with audiovisual material in class is not "easy". The traps set by spontaneous readings of audiovisual texts bring to bear the need for the passage from naive conceptions to disciplinary thought. In order for audiovisual material to become a powerful tool in the exercise of complex thought, these traps have to be dealt with.
\end{abstract}

\section{Las trampas de lo audiovisual en la enseñanza}

Los debates -ya fuertemente arraigados en los estudios sociales- sobre el lugar de los medios y lenguajes audiovisuales en la conformación cultural de nuestras sociedades nos sitúan en la necesidad de analizar nuevamente el uso de lo audiovisual en la enseñanza. Asimismo, consideramos que las miradas sobre este tipo de situaciones particulares nos pueden dar pistas para comprender mejor nuestras prácticas docentes. El presente trabajo surge de una serie de estudios en los que centramos nuestro interés en cómo se produce la apropiación de las formas cotidianas de comunicación en contextos de educación superior, y en particular, en el campo de las Ciencias Sociales. Partimos de algunos reconocimientos que urden la trama sobre la cual un docente construye su clase con la utilización de un video. En primer lugar, un entorno de condiciones prácticas determina la posibilidad de utilización de material audiovisual: duración de la clase, duración del video, accesibilidad a los equipos en el contexto de la institución. En segundo lugar, el docente reconoce en ese material su potencialidad comunicacional. Dicha "potencialidad" puede ser valorada de diversas formas: 
- Por aportes del propio lenguaje audiovisual: entonces, serán las imágenes, los detalles de los fenómenos que transcurren visualmente, o los personajes, sus acciones y escenarios, los que nos traen un impacto estético o emocional que resulta relevante en nuestro campo de conocimiento y enseñanza. El valor potencial del material está dado por esa otra forma de comunicación que "dice" de formas diferentes a las que "dice" la palabra del mismo docente. Se jerarquiza el valor expresivo.

- Por aportes de actualización en el desarrollo de los contenidos: aquí el valor está dado por lo que se dice, no tanto por cómo se lo expresa. Una conferencia dictada por un especialista internacional, los resultados de investigación llevados a video y un documental que sistematiza nuevos aportes de la ciencia. Prima la relevancia del contenido.

- Pero también se puede valorar el potencial comunicacional de lo audiovisual desde otro criterio: por buscar "apropiarse" de las formas cotidianas de comunicación. En este caso, no sólo se argumentan razones de valor sobre el material, sino que también se considera central, encontrar estrategias que potencien los procesos de aprendizaje de los alumnos al aproximarse a sus formas cotidianas de comunicación.

La potencialidad comunicacional que un docente atribuye a un material puede considerar los tres aspectos antes mencionados, pero también, enfatizar un interés u otro según los temas del curso o momentos del proceso de enseñanza. Hemos observado docentes que, con un mismo material audiovisual, instalan sentidos diferentes para su lectura en clase. Indudablemente es la "riqueza" del material la que permite este tipo de cambios en su utilización. En estos casos, el material ofrece una propuesta narrativa y estética que permite diversas aproximaciones al campo de conocimiento. Aquí llegamos al borde de la primer trampa de lo audiovisual: esa "riqueza", esa potencial versatilidad del material para ser mirado, leído, interpretado en diferentes sentidos es percibida por el docente. Pero los novatos en un campo disciplinar no pueden mirar, leer o interpretar lo mismo que un conocedor del tema. La trampa reside en no advertir que lo que para el docente es percepción (percibe lo relevante del campo disciplinar y puede conceptualizar sobre ello), para los alumnos significa un trabajo de construcción cognitiva (en primera instancia, requieren descubrir los indicios relevantes para el fenómeno conceptualizado por el campo disciplinar en cuestión).

Podemos afirmar que las tensiones que se han identificado entre los medios masivos -en particular la televisión- y el sistema educativo, también se expresan al interior de las aulas cuando se introduce un texto audiovisual y el docente se ve en la situación de desarrollar alguna estrategia de intervención que le permita articular ese texto en el discurso de su clase. A partir de nuestro trabajo de investigación, identificamos dos tipos de tensiones que se expresan en estas situaciones: por un lado, las lecturas de los alumnos, apoyadas en la facilidad de la interpretación de lo audiovisual propia de la vida cotidiana, plantean al docente tensiones que lo sitúan ante la necesidad de desarrollar estrategias para el disciplinamiento de la mirada de los estudiantes. Por otro lado, el video introduce otro discurso y otra forma de representación frente a los cuales el docente puede asumir de diversos modos su lugar de autoridad discursiva en la clase. Algunos docentes entrevistados señalan que las dificultades en la interpretación disciplinar de los textos audiovisuales tiene su razón de ser en que los alumnos "no estudian", "no leen", sin embargo, debemos aclarar que el problema fundamental es que no dominan los modos de pensamiento propios de las disciplinas, no saben leer del modo requerido por el pensamiento de las Ciencias Sociales. A través de nuestras entrevistas también encontramos docentes conscientes de las dificultades de conceptualización entre los alumnos y que, paradójicamente, encuentran en lo audiovisual un espacio posible para trabajar con este desafío de la enseñanza superior.

\section{8 - Universidad ORT Uruguay}


Las diferencias entre docente y alumnos respecto al dominio del campo objeto de enseñanza son una asimetría fundante del acto educativo. Esta asimetría se expresa en una profunda distancia entre la lecturas del docente y la de los alumnos sobre un texto audiovisual: se registran diferencias en la identificación de temáticas relevantes al campo disciplinar, en la capacidad de discriminar lo relevante de lo secundario, en la flexibilidad para alternar diferentes puntos de vista en la interpretación de un mismo texto, y en la posibilidad de percibir indicios para la interpretación disciplinar de un texto audiovisual narrativo.

\section{Trabajando con videos argumentativos}

Las expectativas de los docentes respecto a las posibilidades de interpretación y lectura de los alumnos sobre un documental suelen ser muy distantes de lo que los alumnos alcanzan a percibir y reconocer en un material audiovisual de este tipo. En nuestra investigación, al preguntar a los alumnos y a los docentes qué temas trata un video se obtienen respuestas de distinto grado de complejidad. Por ejemplo, en uno de los casos estudiados, sobre un documental de historia, alumnos que visualizaron el material sin acompañamiento docente, identificaban claramente dos temas: inmigración y relaciones entre clases sociales. Por su parte, un docente entrevistado sobre el mismo material mencionaba muchos más temas, enfoques y perspectivas: "El video es útil para poder percibir el modelo de país que se gesta a partir de 1880 y las relaciones sociales que se establecen. (...) En cuánto a los contenidos: la transformación que se produce en el mundo a partir de 1850 con la segunda revolución industrial; la movilización de masas inmigratorias; la creación de la Argentina moderna dentro del esquema de división internacional del trabajo; el rol del Estado; las relaciones entre los distintos grupos sociales; los sectores aristocráticos o elitistas; la inmigración; el papel del Estado como regulador de esa actividad".

En otras situaciones, el valor asignado por los alumnos a la actividad mediadora del docente nos habla de la importancia de la orientación en la lectura de textos argumentativos en clase: los alumnos valoran cuando el docente les ayuda a redescubrir segmentos que se tornan ejemplos de las reflexiones teóricas, o nuevos puntos de vista que los llevan a resignificar afirmaciones o escenas del video.

\section{EI uso de textos audiovisuales narrativos}

Los géneros discursivos argumentativo y ficcional implican problemáticas diferentes para su uso en clase. J. Bruner (1988) considera que estos dos grandes géneros, el argumentativo y el ficcional son, incluso, modos de pensamiento diferentes.

En el caso de un video documental o instruccional, que refiere al mismo campo temático de la materia, el docente podrá recurrir a él para ejemplificaciones o análisis de la temática asumiendo el mismo punto de vista planteado por el video o proponer otros. Sin embargo, cuando el video que se introduce en la clase es un material audiovisual narrativo, como por ejemplo un film de ficción o segmentos elegidos de películas, el campo referencial ficcional deberá ser transfigurado por la interpretación disciplinar.

Umberto Eco acuñó el término de "lectura aberrante" para denominar aquellas situaciones en las que el lector "rompe con el contrato comunicacional", prescinde de la intencionalidad comunicativa que el autor plasmó en su texto e interpreta "libremente" sus significados y sentido. Los estudios sobre los medios de comunicación vienen mostrando que en la vida cotidiana no existe otra lectura que la aberrante. 
Esto es lo que plantea González Requena sobre la lectura del discurso televisivo (González Requena, 1995) y lo que ya hace tiempo sostenía M. De Certeau en su crítica a la "lectura literal". De Certeau sostenía que la lectura literal es producción de una élite, la intelectual, y afirma que existe una literalidad reconocible y por tanto una intencionalidad impresa en el texto por el autor. La lectura literal sería tan sólo un tipo de lectura ejercida por ciertos sujetos que buscan arrogarse el poder de la razón. En la vida cotidiana, existen lecturas: el lector "... inventa en los textos algo distinto de lo que era su intención. Los separa de su origen (perdido o accesorio). Combina sus fragmentos y crea algo que desconoce en el espacio que organiza su capacidad de permitir una pluralidad indefinida de significaciones. Esta actividad "lectora" está reservada al crítico literario (siempre privilegiado por los estudios sobre la lectura), es decir, otra vez a una categoría de intelectuales, o ¿puede extenderse a todo consumo cultural? Esa es la cuestión a la cual la historia, la sociología o la pedagogía escolar deberían aportar elementos de respuesta" (De Certeau, 1996; 182).

Si bien el texto convoca ciertas lecturas y no otras, la interpretación puede independizarse del tipo de texto que sea y asumir una mirada "ficcionalizante" (leer como ficción lo documental) o "documentalizante" (leer como documental la ficción) (Aumont, 1992). Observamos clases en las que a partir de la visualización de segmentos de películas de ficción se busca el trabajo reflexivo de los alumnos. Observamos en dos clases diferentes que los docentes consideraban que lo que estaban pidiendo a los alumnos era algo "fácil". Sin embargo, los alumnos mostraban importantes dificultades para la resolución de las preguntas que se les planteaban.

En una de estas clases se trabajaba la película "Despertares" para analizar el método científico hipotético-deductivo. El relato pone en juego las características principales de dicho procedimiento. Faltan cuatro días para el segundo examen parcial de este grupo y muchos de los alumnos han leído los textos que refieren a estos temas. La docente busca promover el paso de un nivel de lectura anecdótica del video a una segunda lectura conceptual: de la historia de un médico con sus pacientes a una lectura de los pasos que caracterizan un método científico. A través de sus preguntas y aclaraciones va realizando una selección de cuál es la información anecdótica relevante para la ejemplificación de las categorías teóricas. Los alumnos van mostrando en sus intervenciones que comprenden cuál es la información que la docente considera relevante, pero igualmente muestran dificultades a la hora de expresar de modo "disciplinado" (o disciplinar) la interpretación del relato fílmico. No logran precisar en términos lógicos los enunciados de las hipótesis y en ocasiones tampoco logran expresar la información anecdótica como ejemplificación de las categorías mostrando que se encuentran en un momento de construcción inicial de los conceptos. Los alumnos avanzan por aproximaciones en su comprensión de las categorías, por ejemplo, una vez que comprenden cuál es la hipótesis del médico, pueden señalar, aunque no la logran expresar formalmente, la hipótesis contraria que sostienen los otros médicos en la película.

La expectativa de que los alumnos "apliquen" categorías ya construidas significa esperar que puedan leer el relato como ejemplo. Sin embargo, cuando los alumnos están comprendiendo los conceptos por primera vez, no logran identificarlos "enredados", como estan, en el nivel anecdótico de la película. La docente va introduciendo diferentes formas de inducirlos a una lectura conceptual. Busca distanciarlos de lo anecdótico explícitamente pidiéndoles generalizaciones, expone las definiciones de los conceptos, y en otros momentos, va induciendo a los alumnos a volver sobre lo anecdótico resignificándolo conceptualmente. Esta es la característica distintiva de este tipo de uso en clase: el diálogo oscila entre lo anecdótico y lo conceptual de modo constructivo.

\section{0 - Universidad ORT Uruguay}


Para los alumnos, este video es leído como si fuera un "caso": Ios alumnos expresan diversidad de significados que van siendo afianzados, retomados o rechazados por la docente, orientando ésta la "interpretación" del texto audiovisual. Interpretación que en última instancia, para la docente es una ejemplificación de categorías, pero para los alumnos es reconstrucción de las nociones objeto de estudio.

Adriana, una alumna entrevistada, explica su nueva forma de ver una película de ficción en el contexto de esta materia: "la vi desde otro lugar, empecé a ver qué se estaba buscando, como se buscaba...".

En este sentido, consideramos que se instala un proceso de disciplinamiento de la lectura: la docente introduce algunas pistas para orientar la interpretación de los alumnos, recurre intuitivamente a diversas estrategias de andamiaje. El docente busca en su trabajo con el video en clase lograr que el alumno pueda leer e interpretar lo visto desde un marco disciplinar. En este sentido hablamos de un disciplinamiento de la mirada. Utilizamos el término disciplinamiento en su ambigua significación que refiere a disciplina científica o campo de conocimiento, y que también refiere a subordinación y obediencia a un orden.

De hecho, si el docente no orienta un modo de lectura que refiera a su campo de enseñanza, los alumnos perciben y manifiestan el vaciamiento de sentido en la clase: "No viene mal mirar una película, pero es algo a lo que uno busca un sentido". El disciplinamiento de la mirada es la tarea que justifica la introducción del video en clase, aunque la finalidad específica y las formas como se expresa este disciplinamiento en clase pueden diferir notablemente entre sí.

Cuando un docente busca que a través de un material de ficción los alumnos puedan "visualizar conceptos" o "ejemplificarlos", se plantea un problema didáctico ya que los conceptos construidos sobre diferentes fenómenos no se evidencian en una secuencia de una película ficción. Si entendemos por evidencia el presentarse o manifestarse de un objeto cualquiera como tal, como hecho objetivo, no ligado a la claridad y distinción de las ideas (Abbagnano, 1995), se puede caer en la trampa de lo audiovisual ya que "la retórica de la imagen devuelve hechos que parecen evidentes" (Masterman, 1993).

Rudolf Arnheim explica importantes diferencias en el uso de la imagen en el campo del arte y en el campo del pensamiento y el aprendizaje de otros campos disciplinares. Señala que mientras en el arte la imagen constituye la enunciación, es decir "contiene y exhibe las fuerzas sobre las que informa", en el campo científico la imagen se ofrece para el "reconocimiento del síntoma" en la complejidad de la apariencia. "Armado de la imagen de lo que busca, el cazador, el observador de pájaros, el matemático o el biólogo, lo reconoce en medio de la complejidad de las formas dadas (...). Finalmente el estudiante debe aprender a ver el principio simple de este espectáculo barroco" (Arnheim, 1969; 300-302). De allí que la preocupación de Arnheim va a ser el valor de los modelos y las representaciones esquemáticas que faciliten la comprensión conceptual del alumno. La ambigüedad de la imagen, su pluralidad de sentidos, puede ser una traba a la comprensión. Arnheim habla de imágenes, no de textos audiovisuales. Sin embargo, sus consideraciones nos son de utilidad para pensar sobre las clases con video. 
Poder trabajar con los alumnos sobre esa "complejidad de la apariencia" a través del trabajo con material audiovisual nos ofrece caminos valiosos si el objetivo es lograr el uso del conocimiento disciplinar en nuevas formas de comprensión de situaciones cotidianas. Si el docente organiza su propuesta de enseñanza en este último sentido, propone al alumno un proceso de lectura de lo audiovisual de mayor complejidad y asumirá el lugar de guía que ayuda a descubrir aquellos «síntomas» o indicios del texto que permiten la construcción de una categoría conceptual o de un proceso en un nivel de abstracción diferente al del sentido común.

Esta operación de señalamiento de indicios se observa en el discurso docente. En cada clase observada analizamos si se hacía un uso transparente de las imágenes y también si las imágenes eran tematizadas explícitamente o bien señalizadas en el transcurso de la clase. Entendemos por tematización la mención verbal de imágenes y por señalización las expresiones verbales que indican su presencia (a través de expresiones como "esto que vemos aquí..."). En situaciones de utilización de documentales o videos instruccionales, tiende a plantearse un uso transparente del texto y las imágenes muy rara vez son tematizadas o señalizadas. Predomina la tematización de los contenidos disciplinares expresados en el video, mientras el texto audiovisual tiende a ser silenciado en su dimensión de representación. Cuando el video es ficcional, la señalización e interpretación de las imágenes cobra protagonismo en la interacción verbal de la clase.

¿Debemos alegar sobre el derecho de los docentes a estas lecturas aberrantes de las producciones cinematográficas de ficción? El disciplinamiento de la mirada en estos casos implica la pérdida de la ficción ya que el relato pierde sentido bajo la mirada documentalizante. Esta forma de trabajo puede catalogarse bajo lo que despectivamente se ha denominado "pedagogización" de la imagen, es decir la reducción de su abanico semántico a significados unívocos y precisos que aseguren la comprensión esperada por el docente.

Más allá de que consideramos que efectivamente este tipo de experiencias puede ser sumamente enriquecedor para la comprensión de los alumnos, pareciera sin embargo que los relatos se resisten a perder su sentido. Recuperando las palabras de un entrevistado, quedan cosas que no se pueden "enganchar" en la clase. Lo que no "engancha", lo que queda como comentario al margen, pero queda, es la propia historia de ficción frente a la cual el docente suele sentir la necesidad de "contar el final".

En otras ocasiones, puede suceder que el video instale temas o problemáticas que, sin ser la intención del docente trabajarlas, produce una situación en la que los alumnos adoptan un punto de vista que le cambia la clase al docente. En esos casos, el disciplinamiento de la lectura fracasa o presenta difíciles negociaciones.

\section{Conclusiones}

Contrariamente a la creencia del sentido común docente de que el trabajo con lo audiovisual en clase es "fácil", esta actividad nos tiende algunas trampas. Puede ser herramienta poderosa en el ejercicio del pensamiento complejo, pero estos modos de lectura no son fáciles para el docente ni para los alumnos.

La idea de que el uso de videos o films puede facilitar al docente la enseñanza de temas de difícil comprensión ha sido de la mano de la noción de "ayuda audiovisual". El estudio que realizamos nos lleva a abandonar la idea de ayuda en contextos de enseñanza superior: el video en clase es otro discurso que requiere del docente un trabajo de articulación en la construcción de su clase y de mediación en la lectura de los alumnos.

\section{2 - Universidad ORT Uruguay}


Mientras que para el docente no es "ayuda" en el sentido de facilitar la tarea de enseñanza (y eso lo demuestra también el escaso uso educativo del video en general), los alumnos sí lo conciben como ayuda a la comprensión. Los medios audiovisuales ofrecen a los alumnos acercamientos a la comprensión de las disciplinas de las Ciencias Sociales en tanto les ayudan a obtener visiones globales, detectar temáticas importantes, y grabar imágenes en la memoria que luego les facilitan la recordación de los temas así como la posibilidad de realizar reelaboraciones posteriores sobre su significado. Sin embargo, el aprendizaje de modos de lectura que impliquen procesos cognitivos de mayor complejidad, se hace posible en contextos de interacción donde los estudiantes puedan descubrir y construir este otro tipo de lecturas. Si exploramos el terreno de las trampas que tiende lo audiovisual, las dificultades de conceptualización de los alumnos encuentran la posibilidad de exponerse en clase al dar lugar a la expresión de lecturas construidas desde miradas espontáneas de la cotidianidad. Si el docente ejerce esta suerte de disciplinamiento de la mirada, abre posibilidades para que los alumnos puedan distinguir diferentes puntos de vista, focalizar objetos de conocimiento en la complejidad de la experiencia perceptual y reconstruirlos teóricamente como fenómenos de las Ciencias Sociales.

\section{Bibliografía:}

Abbagnano, N. 1995. Diccionario de Filosofía. México: Fondo de Cultura Económica.

Arnheim, R. 1985. El pensamiento visual (1ra ed. 1969). Buenos Aires: Eudeba.

Aumont, J. 1992. La imagen. Barcelona: Paidós.

Bruner, J. 1988. Realidad mental y mundos posibles. Barcelona: Paidós.

Jacquinot, G. 1995. La télévisión: terminal cognitif", en: Réseaux № 74, Dossier: Télévision et apprentissages, nov./déc. 95, pp. 11-29.

De Certeau, M. 1996. La invención de lo cotidiano 1. Artes de Hacer. México: Universidad Iberoamericana, A. C.

González Requena, J. 1995. El discurso televisivo. Madrid: Ed. Cátedra.

Litwin, E. (comp. 1995). Tecnología Educativa: política, historias, propuestas. Buenos Aires: Paidós.

Martín-Barbero, J. 1999. Retos culturales: de la comunicación a la educación, en: Gaceta No 44/45, enero/abril 1999, pp. 4-11.

Masterman, L. 1993. La enseñanza de los medios de comunicación. Madrid: La Torre.

Roig, H. 2002. Lectura de textos audiovisuales y prácticas educativas: el aula universitaria como contexto particular de recepción. Tesis de Doctorado, Facultad de Filosofía y Letras, UBA.

* Doctora en Educación. Licenciada en Psicología. Docente en el Área de Tecnología Educativa e investigadora del IICE de la Universidad de Buenos Aires. 